Janssen, Merck, Novartis, Pfizer, Sanofi, Gilles Boire Grant/research support from: Merck Canada (Registry of biologices, Improvement of comorbidity surveillance) Amgen Canada (CATCH, clinical nurse)

Abbvie (CATCH, clinical nurse)

Pfizer (CATCH, Registry of biologics, Clinical nurse)

Hoffman-LaRoche (CATCH)

UCB Canada (CATCH, Clinical nurse)

BMS (CATCH, Clinical nurse, Observational Study Protocol IM101664. SEROPOSITIVITY IN A LARGE CANADIAN OBSERVATIONAL COHORT)

Janssen $(\mathrm{CATCH})$

Celgene (Clinical nurse)

Eli Lilly (Registry of biologics, Clinical nurse), Consultant of: Eli Lilly, Janssen, Novartis, Pfizer, Speakers bureau: Merck, BMS, Pfizer, Glen Hazlewood: None declared, Carol Hitchon Grant/research support from: UCB Canada; Pfizer Canada, Edward Keystone Grant/research support from: AbbVie, Amgen, Bristol-Myers Squibb, F. Hoffmann-La Roche Inc, Gilead, Janssen Inc, Lilly Pharmaceuticals, Pfizer Pharmaceuticals, Sanofi-Aventis, Consultant of: AbbVie, Amgen, AstraZeneca Pharma, Biotest, Bristol-Myers Squibb Company, Celltrion,

Crescendo Bioscience, F. Hoffmann-La Roche Inc, Genentech Inc, Gilead, Janssen Inc, Lilly

Pharmaceuticals, Merck, Pfizer Pharmaceuticals, Sandoz, UCB., Speakers bureau: Amgen, AbbVie, Bristol-Myers Squibb Canada, F. Hoffmann-La Roche Inc., Janssen Inc., Merck, Pfizer Pharmaceuticals, Sanofi Genzyme, UCB, Diane Tin: None declared, Carter Thorne Consultant of: Abbvie, Centocor, Janssen, Lilly, Medexus/Medac, Pfizer

, Speakers bureau: Medexus/Medac, Vivian Bykerk: None declared, Janet Pope Grant/research support from: AbbVie, Bristol-Myers Squibb, Eli Lilly \& Company, Merck, Roche, Seattle Genetics, UCB, Consultant of: AbbVie, Actelion, Amgen, Bayer, Boehringer Ingelheim, Bristol-Myers Squibb, Eicos Sciences, Eli Lilly \& Company, Emerald, Gilead Sciences, Inc., Janssen, Merck, Novartis, Pfizer, Roche, Sandoz, Sanofi, UCB, Speakers bureau: UCB DOI: 10.1136/annrheumdis-2020-eular.2063

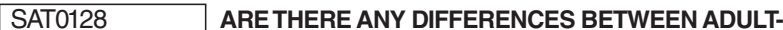 ONSET RHEUMATOID ARTHRITIS PATIENTS AND LATE- ONSET RHEUMATOID ARTHRITIS PATIENTS INTERMS OF USE OF BIOLOGICAL DRUGS AND DRUG RETENTION RATE? RESULTS FROM THE TURKBIO REGISTRY}

A. Yazici ${ }^{1}$, A. Cefle ${ }^{1}$, E. Dalkılıç ${ }^{2}$, G. Can $^{3}$, S. Senel ${ }^{4}$, S. S. Koca ${ }^{5}$, N. Inanc ${ }^{6}$ B. Goker ${ }^{7}$, S. Yılmaz ${ }^{8}$, S. Akar ${ }^{9}$, O. Soysal ${ }^{10}$, Y. Pehlivan ${ }^{2}$, M. A. Ozturk ${ }^{7}$, I. Sari ${ }^{3}$, H. Direskeneli ${ }^{6}$, F. Onen ${ }^{3}{ }^{1}{ }^{1}$ Kocaeli School of Medicine, Rheumatology, Kocaeli, Turkey; ${ }^{2}$ Uludag School of Medicine, Rheumatology, Bursa, Turkey; ${ }^{3}$ Dokuz Eylul School of Medicine, Rheumatology, Izmir, Turkey; ${ }^{4}$ Erciyes School of Medicine, Kayseri, Turkey; ${ }^{5}$ Firat School of Medicine, Rheumatology, Elazıg, Turkey; ${ }^{6}$ Marmara School of Medicine, Rheumatology, Istanbul, Turkey; ${ }^{7}$ Gazi School of Medicine, Rheumatology, Ankara, Turkey; ${ }^{8}$ Selçuk School of Medicine, Rheumatology, Konya, Turkey; ${ }^{9}$ Katip Celebi School of Medicine, Rheumatology, Izmir, Turkey; ${ }^{10} \mathrm{Celal}$ Bayar School of Medicine, Rheumatology, Manisa, Turkey

Background: Rheumatoid arthritis $(\mathrm{RA})$ is one of the most frequent rheumatic disease, and the age of onset is between 30-50 years old. Late-onset RA(LORA) is usually defined as RA with onset at age 60 or over.

Objectives: To investigate the choice, effectiveness and the retention rate of biological drugs in LORA patients.

Methods: TURKBIO registry is the Turkish version of Danish DANBIO rheumatological database which has been established in 2011. We studied RA patients in TURKBIO registry cohort between the dates of 2011 and 2020. All patients fulfilled the American College of Rheumatology criteria for RA and were classified into two groups based on their age at symptom onset: adult-onset $R A(>18-<60$ years; AORA) and LORA( $\geq 60$ years). In both groups, demographical, clinical and laboratory variables; disease activity, current and previous treatment were compared.

Results: From 10 centers, 2111 RA patients recruited, and $8.8 \%$ of them was LORA patients. In LORA, the frequency of female was less than AORA. While, there was no difference between LORA and AORA in terms of erosion presence and RF positivity, antiCCP positivity was more frequent in LORA group. The use of antiTNF was lower, and the use of rituximab was more frequent in LORA. At 12 months after bDMARDs therapy, serum CRP and ESR levels and DAS28CRP showed higher changes compared to baseline values in LORA. Although the mortality rate was higher in LORA, the adverse reactions were reported to be higher in AORA, and most common advers reaction was infections in both groups(Table). The longest survival was observed in infliximab and rituximab(median 22 and 20months) in LORA, in rituximab and golimumab(median 16 and 12 months) in AORA.
Table. Comparison of demographic, laboratory findings and biological treatment

\begin{tabular}{|c|c|c|c|}
\hline $\begin{array}{r}\text { (median;25-75) } \\
\mathrm{n}(\%)\end{array}$ & $\begin{array}{c}\text { AORA }(<60) \\
(n: 1925)\end{array}$ & $\begin{array}{l}\text { LORA }(\geq 60) \\
(n: 186)\end{array}$ & $p$ \\
\hline Age (year) & $54(43-61)$ & $71(68-74)$ & $<0.001$ \\
\hline Disease duration (year) & $11.4(7-18)$ & $6(4-9)$ & $<0.001$ \\
\hline Gender (Female) & $1562(81)$ & $124(67)$ & $<0.001$ \\
\hline Anti-CCP positivity & $747(62)$ & $65(72)$ & 0.044 \\
\hline RF positivity & $721(61)$ & $63(70)$ & 0.085 \\
\hline Erosion presence & $486(56)$ & $41(62)$ & 0.955 \\
\hline Drug survival (months) & $18(6-44)$ & $18(4-31)$ & 0.046 \\
\hline \multicolumn{4}{|l|}{ Concomitant csDMARDs } \\
\hline MTX & $629(34)$ & $39(22)$ & 0.001 \\
\hline SZP & $146(8)$ & $13(7)$ & 0.781 \\
\hline LEF & $501(27)$ & $35(20)$ & 0.032 \\
\hline \multicolumn{4}{|l|}{ bDMARDs } \\
\hline AntiTNF & $1068(56)$ & $73(39)$ & $<0,001$ \\
\hline TCZ & $304(16)$ & $20(11)$ & 0,069 \\
\hline TOFA & $294(15)$ & $27(15)$ & 0,784 \\
\hline RTX & $439(23)$ & $57(31)$ & 0,016 \\
\hline ABA & $298(16)$ & $34(18)$ & 0,317 \\
\hline Response $\Delta \mathrm{ESH}$ & $-6(-21-4)$ & $-18(-36--3)$ & 0.016 \\
\hline (12 months) $\Delta$ CRP & $-2(-12-0.6)$ & $-9.3(-28--0.1)$ & 0.014 \\
\hline$\triangle \mathrm{DAS} 28-\mathrm{CRP}$ & $-1.3(-3--0.1)$ & $-2.2(-3--1)$ & 0.023 \\
\hline$\triangle \mathrm{HAQ}$ & $-0.3(-0.8-0)$ & $-0.4(-0.8--0.1)$ & 0.114 \\
\hline Adverse effects & $440(23)$ & $32(17)$ & 0.077 \\
\hline Malignancy & $9(0,5)$ & $3(1.6)$ & 0.082 \\
\hline Infection & $192(10)$ & $10(5)$ & 0.042 \\
\hline Allergy & $63(3)$ & $4(2)$ & 0.404 \\
\hline Dermatitis & $62(3)$ & $1(0,5)$ & 0.040 \\
\hline Death & $18(0.9)$ & $7(4)$ & 0.004 \\
\hline Other & $136(7)$ & $11(6)$ & 0.556 \\
\hline
\end{tabular}

Conclusion: The frequency of LORA who uses bDMARDs was $8.8 \%$ in our database. In the elderly patient population, there are some reservations about the use of biological drugs in general due to several co-morbidities and concommitant drug used. Although data on this issue are limited, appropriate biological use can be effective and reliable in required patients.

References:

[1] Zulfigar AA, Niazi R, Pennaforte JL, Andres E. Late-onset rheumatoid arthritis: clinical, biyological, and therapeutic features about a retrospecttive study. Geriatr Psychol Neuropsychiatr Viell 2019;17:51-62

Acknowledgments : None

Disclosure of Interests: : None declared

DOI: 10.1136/annrheumdis-2020-eular.1625

\section{SAT0129 ROLE OF SHARED EPITOPE ON THE EFFECTIVENESS OF TNFI TREATMENT FOR PATIENTS WITH RHEUMATOID ARTHRITIS}

J. Zhuo $^{1}$, J. Bryson ${ }^{1}$, Q. Xia ${ }^{1}$, N. Sharma ${ }^{2}$, C. Samal ${ }^{2}$, S. Lama ${ }^{1}$, M.

E. Weinblatt ${ }^{3}$, N. Shadick ${ }^{3}{ }^{1}$ Bristol-Myers Squibb, Lawrenceville, United States of America; ${ }^{2}$ Mu-Sigma, Bangalore, India; ${ }^{3}$ Brigham and Women's Hospital, Boston, United States of America

Background: Rheumatoid arthritis (RA) has been shown a strong genetic association with particular HLA-DRB1 alleles containing shared epitope (SE). However whether SE is clinically useful in treatment choices is insufficiently investigated and previous studies have presented mixed findings in the role of SE in the response of TNFi therapies ${ }^{2,3}$

Objectives: To assess the role of SE in response to TNFi treatment in real-world RA patients (pts)

Methods: Pts enrolled in a large RA registry, Brigham and Women's Hospital RA Sequential Study, with known SE and received TNFi therapies were included for the analysis. TNFi pts were identified by the first-time use of the drugs between March 2003 to June 2018. For this analysis, all pts were followed up to 1 year. Summary statistics are reported for demographics, serostatus and disease activity (DA) at baseline and follow-up, stratified by SE status. Given the strong association of SE and anti-citrullinated protein antibody (ACPA), the analysis was further stratified by ACPA status. The effect of SE on change in DA was assessed using linear regression model with age, gender, RA disease duration, baseline DA, smoking status, SE, ACPA and ACPA-SE interaction as covariates.

Results: Of the $484 \mathrm{TNFi}$ pts included in the study, $68.8 \%$ were SE+. SE+ pts (vs SE-) were more likely to be rheumatoid factor positive, have erosive 